\title{
COMPARISON OF PARTICLE SHAPES OF CONVENTIONALLY GROUND BARITE, CALCITE AND TALC MINERALS BY DYNAMIC IMAGING TECHNIQUE: A REVIEW
}

\author{
Ugur Ulusoy \\ Department of Mining Engineering \\ Division of Mineral Processing \\ Sivas Cumhuriyet University \\ Sivas, Turkey, 58140 \\ uulusoy@cumhuriyet.edu.tr
}

\begin{abstract}
Shape of particles made by grinding is one of the important measures for determining the utilizations of industrial minerals namely barite, calcite, and talc particles, particularly at production (like coating pigments, paints, rubber and paper) and processing stages (beneficiation by flotation). Therefore, measurement of particle characteristics is a critical issue in the development and control of industrial mineral products in most of the industries for some demanding applications. Ball and rod mills are commonly used as conventional grinding mills to produce a controlled grind size for the flotation circuit in the beneficiation of industrial minerals. Dynamic Image Analysis (DIA) offers reproducible results of a huge number of particles for some industrial minerals namely, barite [1], calcite [2] and talc [3] particles, whose shapes are crucial for some industries utilized as fillers. Thus, this review is about the comparison of shape values in terms of circularity (C) and bounding rectangle aspect ratio (BRAR) determined by the real time DIA. It was found that the shape results of the previous studies for the same samples by SEM measurement [4] were in good agreement with DIA results. It was concluded that the more rounded particles were encountered in the rod milled products for calcite and barite minerals. On the other hand, the more elongated particles were found in the ball milled products for talc mineral. It was attributed to the material type since the same mills were used for all tests. Hence, DIA can be used as a useful tool, which is easy, fast and highly accurate to control the particle shape distributions whether the required powder is fit for use.
\end{abstract}

Keywords: barite, calcite, talc, ball mill, rod mill, particle shape, DIA.

DOI: $10.21303 / 2461-4262.2020 .001406$

\section{Introduction}

Precise ensuring of raw materials, intermediate and final products becomes vitally necessary since demands for product quality are gradually increasing. The attributes of industrial minerals being traded are frequently contingent on the attributes at the particle level [1-5]. The evaluation of distributions of size, shape, and structure is a critical step in process control and product specification.

Raw materials used in industry in variously prepared forms as minerals like calcite, barite, and talc are called as industrial minerals whose unit value is low but the purity is great, almost chemical grade. The world production of barite, limestone and talc was reached to 9.5, 420 and 7.5 (million metric tons) respectively, in 2018 [6].

These minerals give some superior properties such as high brightness, high chemical or mineralogical purity, lower abrasivity, low oil absorption, low moisture, easy dispersion, high opacity, and improved printability due to its good ink receptivity [7]. Calcite, barite and talc are main industrial minerals used for many industries like paper, paints, plastics and coatings to improve properties. For paper making filler ground limestone and chalk forms of calcium carbonate and talc are the most widely used materials obtained by mining [8].

Processing of these industrial minerals according to the knowledge of their physical properties to value added grades is essential. Flotation is employed to finely ground them. They may be micronized by ultra-fine pulverizing [9]. They are consumed instantly for industrial applications as soon as they are separated from their gangues that should be low. They are mined 
and micronized by comminution for the production of filler materials in many fields principally paint, paper, plastic due to their superior property like whiteness and cheapness. For instance, high quality filler grades of them are achieved by flotation after grinding because of their attributes, namely white color, and a high purity, with controlled particle size, shape, surface area, and liquid absorptivity.

Micronized talc is generally favored in architectural paints and industrial paints. Particle shape is one of the affecting criteria for the addition of these minerals as fillers to paints, plastics, rubber, papers and coating industry [7, 10,11]. Each particle shape of industrial minerals gives certain advantages to the product. For example, tabular and irregular particle shape is favored in ground barite for the utilization as filler in the industry due to its good reinforcement and packing density [12]. Most filler minerals can be categorized as platy or blocky in shape. Representatives of the platy and blocky shape of materials used as fillers for paper can be given by talc and, ground calcium carbonate (GCC), respectively. It is also possible to obtain blocky, and acicular or needle-like shape of precipitated calcium carbonate (PCC) by changing conditions of production [8]. Whilst flaky talc particles are required for filler industry, prismatic talc, which provides better durability in exterior and traffic paints, is desired to give well dispersion, greater loading levels, and greater dry hide than platy talc [7]. Typical particle shape and aspect ratio (length/width) values of GCC (limestone) and talc for paper making fillers can be varied as irregular - blocky, platy and 1 to $1.5,5$ to 20 , respectively [8].

The primary rationality for particles characterization is to attain the same throughput in structure or composition of products desired. By the evolution of SEM, paper industry noticed the differences in typical shapes between various types of filler minerals. However, shape characterization of platy particles needs reliable technique since microscopic technique measures two-dimensional images [8] and becomes impractical for particle analysis to examine a thousand of particles due to slowness and tedious. Therefore, automated image analyzing systems with high sample throughput and short measurement times becomes an ideal tool for routine analyses and quality control for the particle characterization, which can be performed at numerous distinct stages (from the processing stages to transportation of the products) provision. Dynamic Image Analysis (DIA) has recently been widely used for the characterization of various materials not only ores and minerals but also tailings [1, 2, 13-15]. In a recent study [16] dynamic image analysis was used to characterize the morphology of 45 mineral fertilizers, with grain shapes ranging from highly irregular to nearly spherical. Most relevant parameters like Circularity and Angularity were calculated as outputs of the image-processing treatment. In another study, [17], the shapes of particles were determined by digital image processing techniques for comparison between four tailings (gold, tin, copper, and iron) and two natural sands (river sand and sea sand). The differences of physical and mechanical properties between tailings and natural sands were described in terms of shape descriptors such as elongation, sphericity, convexity, and roughness. Mineral processing is known as the separation of the valuable minerals from gangue minerals to produce a concentrate and a tailing. It is carried out by complicated processing steps involving grinding to the liberation size for individual minerals can be attained by a selected further separation like flotation.

In the last stage of comminution, the particle size of lumps ores is generally reduced gradually by conventional grinding mills to achieve good liberation for the separation techniques determined to increased grade and recovery of the targeted mineral or compound. Conventional grinding usually consists of a rod and ball milling as coarse and fine grinding, respectively. Since the ground product size from a rod mill is much more uniform than a ball mill but the overall size is much coarser, a rod mill (open circuit) generally precedes a ball mill (closed circuit with a classifier) in a grinding circuit especially where a fine size product (like mineral fillers or powders) is required.

As rotating a tumbling mill loaded with lumps of ores and grinding media, the whole grinding charge goes up opposed to the perimeter of the mill in the direction of motion. On attaining a certain elevation, portion of the charge cascades and declines to the lower side of the 
mill, the other portion has a tendency of sliding downwards but before long moves in the direction of mill motion. Then at that time, the media falls down several times to the lumps of ores reduces its size by cataracting. Some comminution also occurs because of abrasion effects. The resultant size reduction happens by the combination of impact and abrasion repetition, and the desired mineral is liberated by the sufficient time of grinding [18]. Balls and rods are used as the grinding media to exert a point and line load, respectively, on the particles. Regarding the rotation speed ball mills operation is based on two distinct regimes namely, cataract and cascade. While cataract favors collisions hence, body breakage, cascade leads to breakage by attrition [19]. In fact, the breakage motion of rod milling nearly resembles to ball milling. The whole length of a rod is the reason for breakage of particles scattered along the mill length. The breakage happens more by the cascading motion than by cataracting. The rods drop from a top level and roll down the mill to ground the materials by breakage forces, namely impact and abrasive [20].

Particle shape is regarded as decisive criteria for production and processing of industrial minerals. Paints, plastics, rubber, paper and coating industries use particles shape characterization techniques for having better knowledge about their products and processes as well as particle size. Especially, in flotation process where attachment of valuable finely ground mineral particles to the air bubbles is demanded [21-28] rounded particles are disadvantaged in the attachment to air bubbles in flotation system [36]. Since ball and rod mills are the most preferred conventional mills to produce micronized industrial minerals and to beneficiate them. The purpose of this work is to review the DIA analysis results of conventionally ground industrial minerals namely calcite [2] talc [3] and barite [1] minerals to utilize the results for the industries such as paints, plastics, rubber, paper as well as for the particle-bubble attachment phenomena of flotation process.

\section{Dynamic Image Analysis (DIA)}

In this review, high grade industrial minerals from Turkey were used to review the real time DIA results by comparing the previously reported works, i. e., barite with $\mathrm{BaSO}_{4}$ content of $97.63 \%$ [1], calcite with $\mathrm{CaCO}_{3}$ content of $99.14 \%$ [2], and talc with $\mathrm{SiO}_{2}$ and $\mathrm{MgO}$ contents of $59.2 \%$ and $30.97 \%$ [3] as shown in Fig. 1, which attests almost pure samples by the XRD plots because particle shape might be affected by the particle mineral composition.

Fig. 2 illustrates the PSDs of the samples ground by ball and rod mills. Since the best flotation performance is generally achieved by the fraction of $250 \times 45 \mu \mathrm{m}$ size, the same size fractions were produced by sieving of the samples ground by conventional mills in this review.

The optimum grinding times were listed Table 1 based on the quantity of minus $250 \mu \mathrm{m}$ size fraction, because minus $250 \mu \mathrm{m}$ size fraction is favorable for the image analysis. In grinding tests, the parameters like $J_{B}, f_{c}$ and $U$ were assumed as $0.2,0.04$, and 0.5 , respectively to give a normal first-order grinding kinetics [29]. Representative samples for the sieve analysis were taken by coning and quartering method using standard laboratory sieves of $800,600,425$, 300, 212, 150, 106, 75, 53, 45 and $38 \mu \mathrm{m}$ (Retsch GmbH, Haan, Germany).

A rotary micro-riffler (Quantachrome ${ }^{\circledR}$ Instruments, Florida, USA), which (Fig. 3, a) is the most reliable technique for sampling $[30,31]$ was used to prepare feeds for the shape analysis of ball and rod milled industrial minerals particles by DIA. It should be noted that the particles should be well dispersed for good measurement of DIA so that they are not touching each other. Therefore, each sample were kept in a glass beaker having a $25 \mathrm{ml}$ volume, added with water and stayed in an ultrasonic bath as shown in Fig. 3, $\boldsymbol{a}$ for a few min to provide excellent dispersion of the representative sample for DIA measurements. Then, a few drops of the prepared suspension drawn by a liquid dropper were used for the DIA.

As shown in Fig. 3, $\boldsymbol{b}$ particles are suspended in a flowing stream, backlit by a highspeed digital camera to view individual particle images directly. Then the shape of particles from all aspects can be measured by capture them for post-run processing (Fig. 4) with random orientation (Fig. 3, c), for quick statistically valid results thanks to the recirculating sample module and precision optics [32]. 
Quantitative particle shape analysis is important for assuring the characteristic property of the material desired for a specific purpose of utilization. Circularity from circle model and BRAR from bounding rectangle model of DIA instrument were selected to compare the shape [1-3] of particles this review.
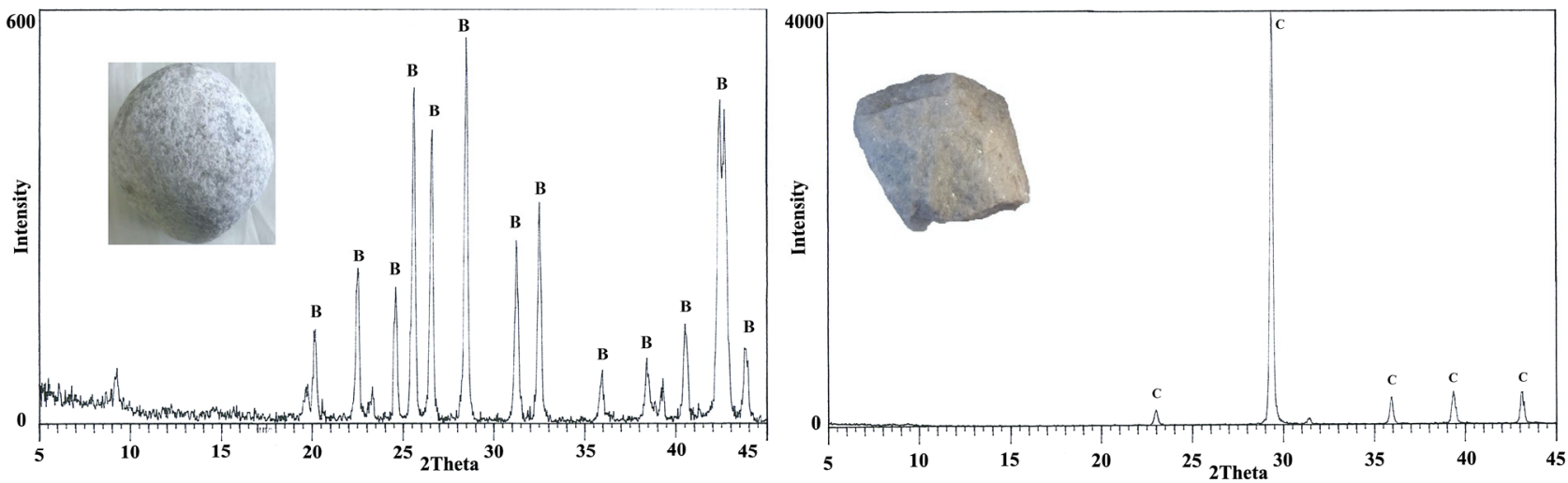

$a$

$b$

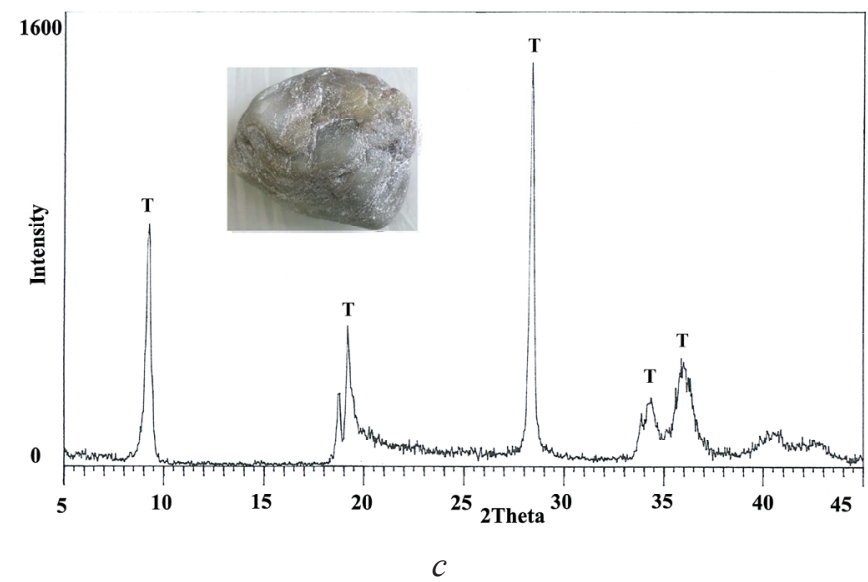

Fig. 1. XRD patterns of the industrial minerals used in this study:

$a$ - barite; $b$ - calcite; $c$ - talc (modified from [33, 34])

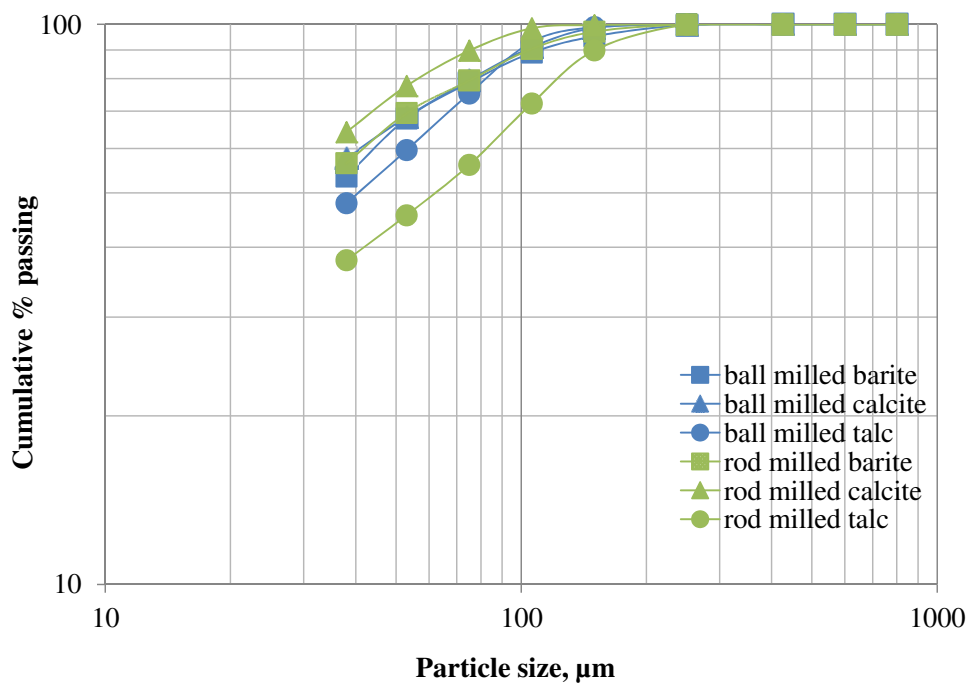

Fig. 2. PSD of barite, calcite, and talc samples studied (data from [33]) 
Table 1

Rod and ball milling conditions of the industrial minerals used in this review (Retabulated from [28, 37])

\begin{tabular}{|c|c|c|c|c|}
\hline Type & Parameters & & Values & \\
\hline \multirow[t]{15}{*}{ Rod Mill } & Mill diameter $D, \mathrm{~mm}$ & & 200 & \\
\hline & Mill length $L, \mathrm{~mm}$ & & 280 & \\
\hline & Mill volume $V, \mathrm{~cm}^{3}$ & & 8792 & \\
\hline & Critical speed $N_{c}, \operatorname{rpm}\left(\right.$ from $\left.N_{C}=42.3 /(D-d)^{1 / 2}\right)$ & & 102 & \\
\hline & Operational speed $\left(50 \%\right.$ of $\left.N_{c}\right)$, rpm & & 51 & \\
\hline & Steel Rods & & & \\
\hline & Rod diameter, mm & & $29,24,19$ & \\
\hline & Average rod weights, $g$ & & $1521,1041,669$ & \\
\hline & Rod density, $\mathrm{g} / \mathrm{cm}^{3}$ & & 7.90 & \\
\hline & Total rod weight, kg & & 22600 & \\
\hline & Industrial Minerals & Barite & Calcite & Talc \\
\hline & Specific gravity, $\mathrm{g} / \mathrm{cm}^{3}$ & 4.50 & 2.70 & 2.70 \\
\hline & Total powder weight, $g$ & 1266 & 759.6 & 759.6 \\
\hline & Grinding time, minute & 8 & 16 & 16 \\
\hline & Feed size, $\mu \mathrm{m}$ & & $(-4750+3350)$ & \\
\hline \multirow[t]{18}{*}{ Ball mill } & Mill diameter $D, \mathrm{~mm}$ & & 200 & \\
\hline & Mill length $L, \mathrm{~mm}$ & & 184 & \\
\hline & Mill Volume $V, \mathrm{~cm}^{3}$ & & 5776 & \\
\hline & Critical speed $N c, \operatorname{rpm}\left(\right.$ from $\left.N_{C}=42.3 /(D-d)^{1 / 2}\right)$ & & 102 & \\
\hline & Operational speed $\left(75 \%\right.$ of $\left.N_{c}\right), \mathrm{rpm}$ & & 76 & \\
\hline & Steel Balls & & & \\
\hline & Balls diameter, mm & & 30,26 & \\
\hline & Average ball weights, $g$ & & $118.18,68.19$ & \\
\hline & Ball density, $\mathrm{g} / \mathrm{cm}^{3}$ & & 7.90 & \\
\hline & $\begin{array}{c}\text { Fractional ball filling, JB (from } J_{B}= \\
=[(\text { mass of balls } / \text { ball density }) /(\text { mill volume })]^{* /[1.0 / 0.6])}\end{array}$ & & 0.2 & \\
\hline & Total ball weight, $\mathrm{kg}$ & & 5.475 & \\
\hline & Industrial Minerals & Barite & Calcite & Talc \\
\hline & Specific gravity, $\mathrm{g} / \mathrm{cm}^{3}$ & 4.50 & 2.70 & 2.70 \\
\hline & Total powder weight, $g$ & 623.8 & 374.2 & 374.2 \\
\hline & Grinding time, minute & 8 & 16 & 32 \\
\hline & $\begin{array}{c}\text { Fractional powder filling, } f_{C} \\
\left(\text { from } f_{c}=[(\text { mass of powder/powder density }) /(\text { mill volume })]^{* /}\right. \\
{[1.0 / 0.6][39]}\end{array}$ & & 0.04 & \\
\hline & Powder-ball loading ratio, $U$ & & 0.5 & \\
\hline & Feed size, $\mu \mathrm{m}$ & & $(-800+600)$ & \\
\hline
\end{tabular}



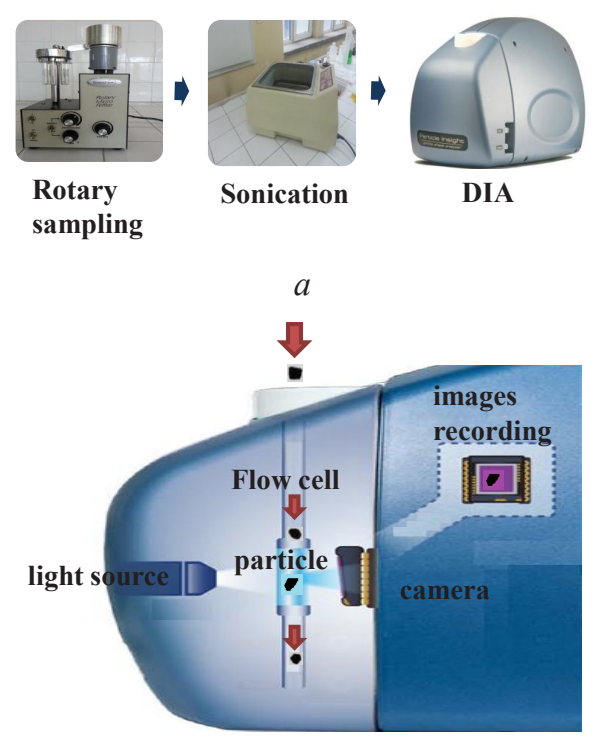

b
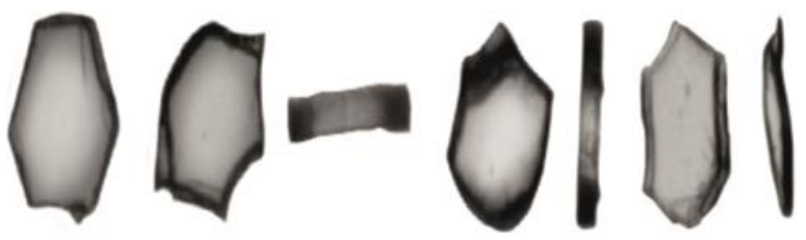

Fig. 3. Dynamic Image Analyzing: $a$-experimental scheme; $b$ - basic principles of operation; $c$-random particle orientation phenomena [4; 32]

P

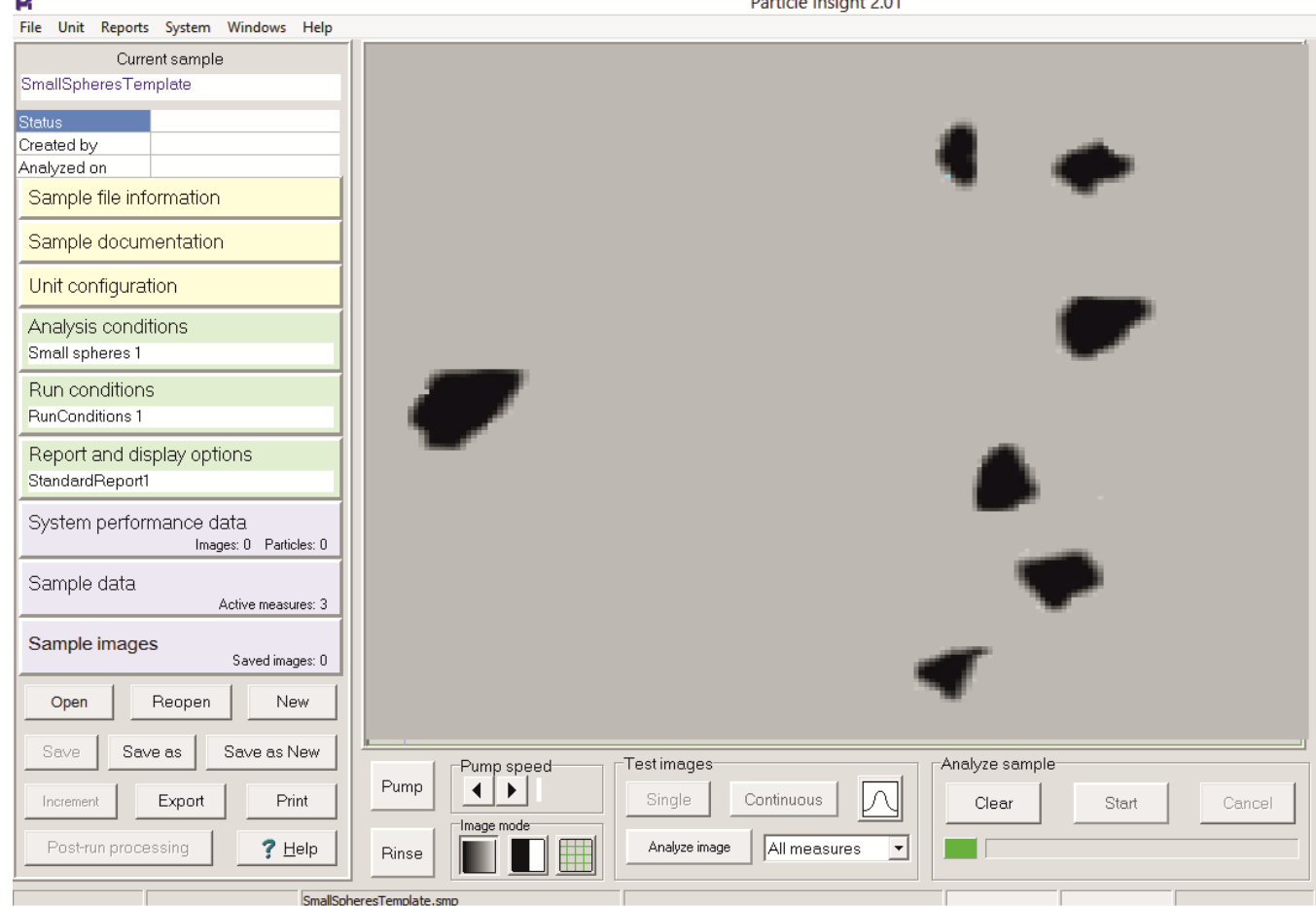

Fig. 4. Screenshot from the program interface used in DIA instrument called Particle Insight 2.01 (Micromeritics $\left.{ }^{\circledR}\right)[32]$ ) 


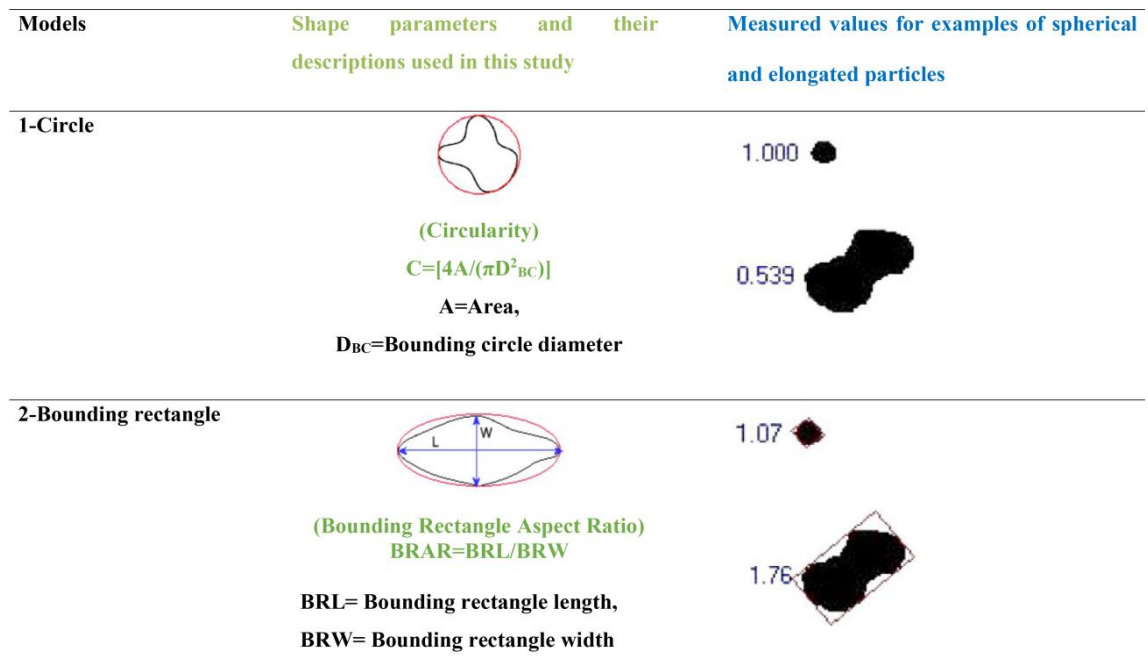

Fig. 5. Shape models used in DIA of industrial mineral particles [39]

Circularity is calculated from the measured area (A) and bounding circle diameter $\left(D_{B C}\right)$ in terms of a fraction of the bounding circle's area covered by the actual shape of the measured particle by DIA (1),

$$
C=4 A / \pi D_{B C}^{2}
$$

Whilst $\mathrm{C}$ values lower than 1 for irregular particles means elongated particles as illustrated by Fig. 5, circularity value near to " 1 " represents mostly round particles in the sample population.

Another shape parameter selected for DIA is BRAR. It is calculated as the ratio of bounding rectangle length to bounding rectangle width [35] (2)

$$
\mathrm{BRAR}=\mathrm{BRL} / \mathrm{BRW} \text {, }
$$

where BRL is the longer side of the bounding rectangle and BRW is the shorter side of the bounding rectangle. The value of BRAR is always greater than 1 for irregular particle and equal to 1 for spherical particle.

\section{Results and discussion}

Fig. 6 illustrates DIA results for differently milled particles of different minerals studied. $\mathrm{C}$ values of rod milled of calcite and barite minerals were higher than $\mathrm{C}$ values (Fig. 6, $\boldsymbol{a}$ ) of ball milled calcite and barite mineral. BRAR values of ball milled talc mineral were higher than BRAR values (Fig. 6, b) of rod milled talc mineral.

The results have shown that rod milled samples includes particles having averagely higher $\mathrm{C}$ values than ball milled samples for both calcite and barite minerals $(R>B)$ while the most of the particles produced by ball mill have higher $C$ than rod milled particles $(B>R)$ for talc mineral. This means ball milled particles like more blocky and rounded $(R>B)$ shape comparing to the rod milled ones for calcite and barite minerals whereas rod milled talc particles mostly as the shape of elongated than ball milled ones $(B>R)$.

The results from Table 2 has shown that talc particles had the highest average value of $C$ of all ball and rod milled mineral particles following the trend as $C_{\text {talc }}>C_{\text {barite }}>C_{\text {calcite }}$. The highest average values of BRAR were obtained by calcite particles of all ball and rod milled mineral particles as the trend of $\mathrm{BRAR}_{\text {calcite }}>\mathrm{BRAR}_{\text {talc }}>\mathrm{BRAR}_{\text {barite }}$. In fact, by definition the value of $C$ is the opposite of the BRAR. Therefore, dissimilar trend for $C$ values is observed comparing to those of BRAR. When comparing the shape of ball and rod milled industrial minerals, ball and rod milled calcite particles had the highest elongated particles. Whereas, ball and rod milled talc particles contain the highest rounded particles. Although the same mills were used for the same industrial minerals 
namely, calcite, barite and talc samples studied, these differences in shape were ascribed to the different type of materials.
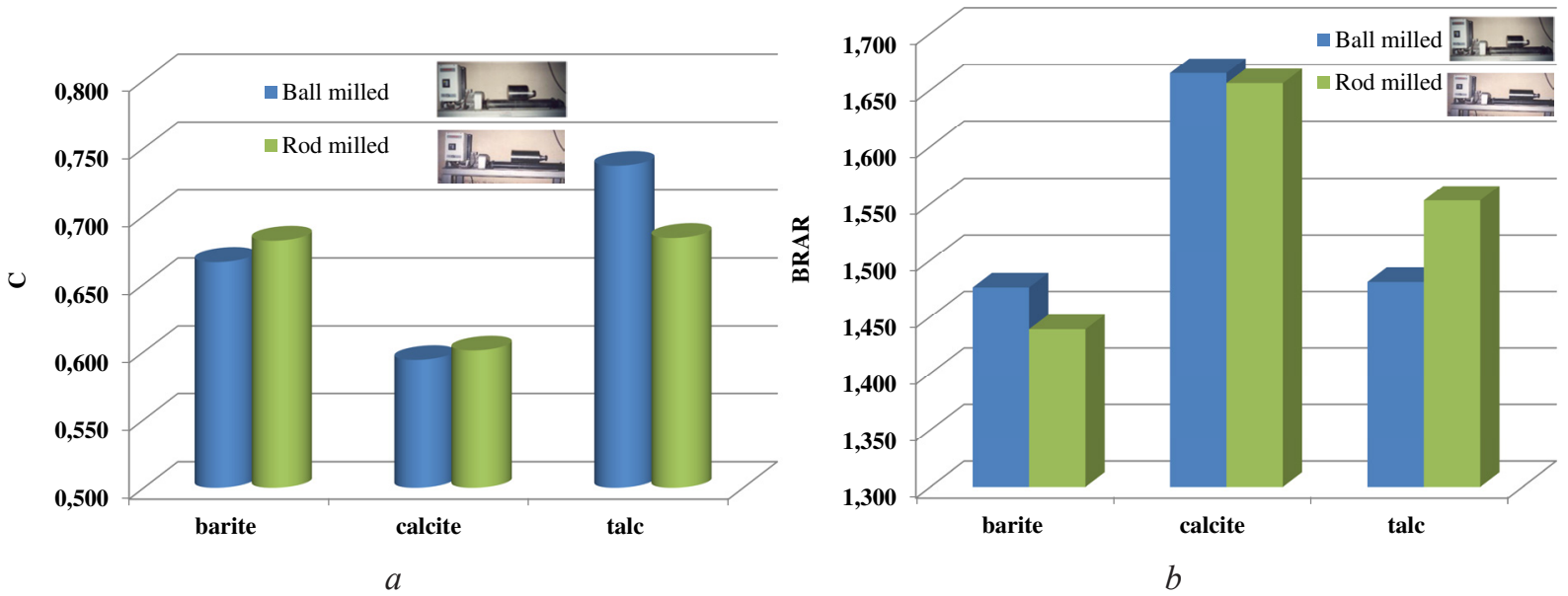

Fig. 6. Comparison of shape results determined by DIA for the particles of conventionally milled industrial minerals (redrawn from [1-3]: $a-\mathrm{C}$ (Circularity); $b-$ Bounding rectangle aspect ratio (BRAR))

Table 2

Released trend order of the shape results by DIA for particles conventionally milled industrial minerals

\begin{tabular}{cc}
\hline Selected Shape Parameter & Trend order of the shape results \\
\hline C & $\mathrm{C}_{\text {talc }}>\mathrm{C}_{\text {barite }}>\mathrm{C}_{\text {calcite }}$ \\
BRAR & $\mathrm{BRAR}_{\text {calcite }}>\mathrm{BRAR}_{\text {talc }}>\mathrm{BRAR}_{\text {barite }}$
\end{tabular}

$\mathrm{C}$ trends based on each milled product are as the order of "talc $>$ barite $>$ calcite", on the other hand, BRAR trends based on each milled product are found as the order of "calcite $>$ talc $>$ barite". This difference in the trends could be attributed to not only different breakage actions of ball and rod milling and grinding conditions used but also to different type of materials and their crystal structure cleavage. This is in good agreement with the previously reported studies [40-45].

Fig. 7 illustrates the shape results by SEM measurements for the same samples. It was concluded that, DIA [1-3] results were in good agreement with the previous studies by SEM measurements [4].
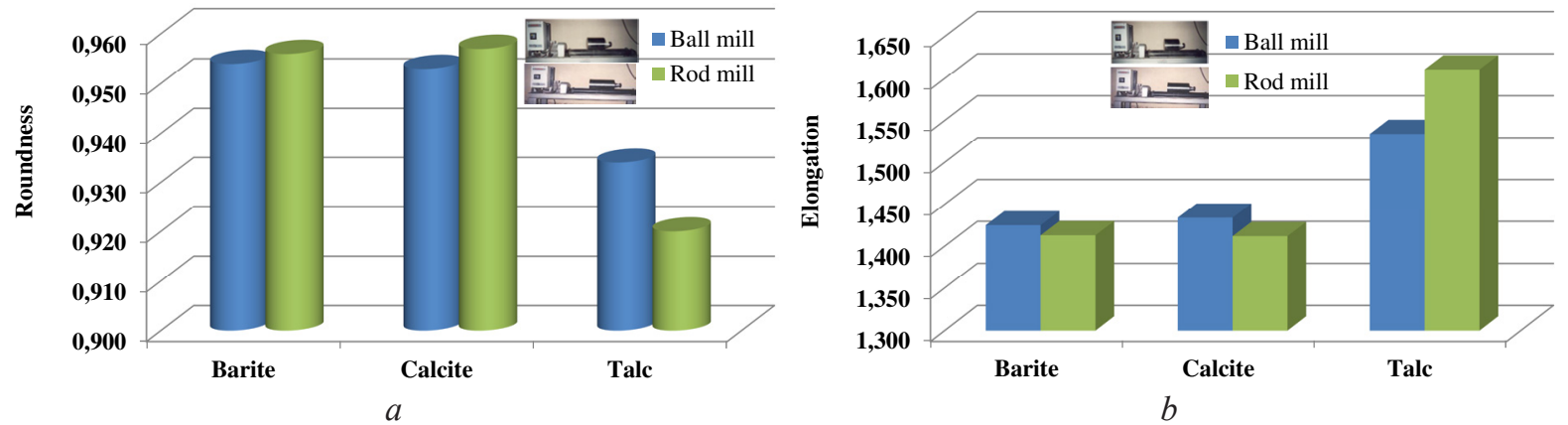

Fig. 7. Comparison of shape values determined by SEM for the same industrial minerals studied ground in conventional mills (redrawn from [4]): $a$ - Roundness; $b$ - Elongation

Fig. 8 shows SEM [4] approach for the shape characterization of the same samples. It should be kept in mind that shape measurements were based on the two-dimensional projection of the particles. Elongation (3) is defined as the ratio of length to the width of the particle projections. Round- 
ness is given by as the ratio of $4 \pi$ times Area to the square of the perimeter (4). In other words, the higher the values of the function, the rounder the shape of the particle projection [47]

$$
\begin{gathered}
E=L / W, \\
\left.R=\left[(4 \pi A) / P^{2}\right)\right] .
\end{gathered}
$$

It can be concluded that DIA is the best technique giving quick and reproducible results to compare shape differences of ball and rod milled particles to control the particle shape distributions whether the required powder is fit for use.

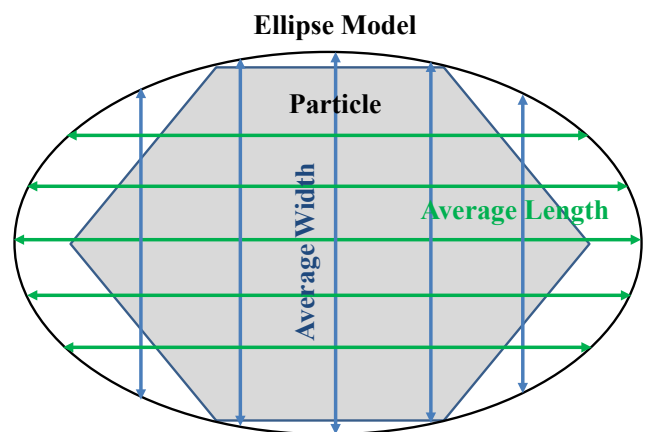

Fig. 8. Calculation of Elongation and Roundness based on 2-dimensional SEM measurements on the projection of the particle assumed like ellipse (modified from [4])

DIA allows statistically significant sampling of great number of particles in each measurement whereas microscopy techniques are time-consuming. It is a high-resolution direct technique to characterize particles quickly at the particle size ranges (45-250 micron), which are suitable for flotation. It can be also useful and it gives to consider which material gives higher floatability in flotation since prismatic particles are favored in their attachment process to the bubble [36]. It analyzes particles while they are in motion and uses several particle characterization models like circle, ellipse, and irregular, since the particle shape is inherently a three-dimensional physical property.

On the other hand, DIA has a disadvantage of using dispersing particles in liquid whilst dry particles are stationary, on a glass slide in static imaging techniques [3].

\section{Conclusions}

As it is well known that, conventional mills, namely are ball and rod mills are widely used in the mineral processing for the size reduction and liberation of the valuable minerals. Thus, in this review, an overview of some recent studies devoted to the shape characterization by DIA technique of some industrial minerals namely, calcite, barite and talc particles produced by conventional mills.

By using the latest technique of imaging (DIA), the most striking shape descriptors, namely Circularity and BRAR were selected to quantify the particle shapes of the industrial minerals and the differences in particle shapes created by conventional milling namely, ball and rod milled were successfully determined and discussed.

Comparing with the results of the previous studies for the same samples by SEM measurement it was also found that the results were in good agreement with each other.

The shape of particles from all aspects can be measured by DIA3-dimensionally with random orientation for quick statistically valid results thanks to the recirculation sample module and precision optics.

DIA can be used an effective tool instead of manual microscopy to provide easiest, fastest and the most accurate results in the characterization of particle shapes as well as quality check of them but in a liquid medium for the particle sizes especially for flotation. So that particle shape can be utilized as the decisive criteria for a specific application like plastics, paint, rubber and paper for calcite, barite and talc particles. 


\section{References}

[1] Ulusoy, U. (2019). Quantifying of particle shape differences of differently milled barite using a novel technique: Dynamic image analysis. Materialia, 8, 100434. doi: https://doi.org/10.1016/j.mtla.2019.100434

[2] Ulusoy, U., Yekeler, M. (2014). Dynamic image analysis of calcite particles created by different mills. International Journal of Mineral Processing, 133, 83-90. doi: https://doi.org/10.1016/j.minpro.2014.10.006

[3] Ulusoy, U. (2016). Dynamic image analysis of differently milled talc particles and comparison by various methods. Particulate Science and Technology, 36 (3), 332-339. doi: https://doi.org/10.1080/02726351.2016.1248261

[4] Ulusoy, U. (2008). Physical Attributes of Particles and Their Roles on Wetting and Flotation. Chap. 9. Fine Particle Technology and Characterization. Kerala, 213-230.

[5] Critchley, L. (2019). Particle Characterization in Mining. Available at: https://www.azomining.com/Article.aspx?ArticleID $=1506$

[6] U.S. Geological Survey (2019). Mineral commodity summaries 2019. doi: https://doi.org/10.3133/70202434

[7] Ciullo, P. A. (1996). The industrial minerals. Industrial Minerals and Their Uses, 17-82. doi: https://doi.org/10.1016/b978081551408-4.50003-X

[8] Hubbe, M. A., Gill, R. A. (2016). Fillers for Papermaking: A Review of their Properties, Usage Practices, and their Mechanistic Role. BioResources, 11 (1). doi: https://doi.org/10.15376/biores.11.1.2886-2963

[9] Kuzvart, M. (2006). Industrial Minerals and Rocks in the 21st Century, 287-303. Available at: http://www.ehu.eus/sem/seminario_pdf/SEMINARIO_SEM_2_287.pdf

[10] Vanderbilt, R.T. (2013). Paints and Coatings. No. 703. Vanderbilt Minerals. Available at: https://www.vanderbiltminerals.com/ resources/VR_703_Paint_Filler_Minerals_Reference_Web.pdf

[11] Lobato, E. M. C. (2014). Chap. 4. Determination of aspect ratio of anisometric talc particles from particle size analysis. Virginia, 130-132.

[12] Wypych, G. (2016). Handbook of Fillers. ChemTec Publishing, 938.

[13] Wilms, A., Knop, K., Kleinebudde, P. (2019). Combination of a rotating tube sample divider and dynamic image analysis for continuous on-line determination of granule size distribution. International Journal of Pharmaceutics: X, 1, 100029. doi: https://doi.org/10.1016/j.ijpx.2019.100029

[14] Bandini, V., Biondi, G., Cascone, E., Di Filippo, G. (2017). Dynamic image analysis of Etna Sand in one-dimensional compression. Measurement, 104, 336-346. doi: https://doi.org/10.1016/j.measurement.2016.07.050

[15] Czajkowska, M., Sznitowska, M., Kleinebudde, P. (2015). Determination of coating thickness of minitablets and pellets by dynamic image analysis. International Journal of Pharmaceutics, 495 (1), 347-353. doi: https://doi.org/10.1016/j.ijpharm. 2015.08.102

[16] Le, T.-T., Miclet, D., Heritier, P., Piron, E., Chateauneuf, A., Berducat, M. (2018). Morphology characterization of irregular particles using image analysis. Application to solid inorganic fertilizers. Computers and Electronics in Agriculture, 147, 146-157. doi: https://doi.org/10.1016/j.compag.2018.02.022

[17] Yang, Y., Wei, Z., Fourie, A., Chen, Y., Zheng, B., Wang, W., Zhuang, S. (2019). Particle shape analysis of tailings using digital image processing. Environmental Science and Pollution Research, 26 (25), 26397-26403. doi: https://oi.org/10.1007/s11356019-05974-6

[18] Perrucci, M., Pischtschan, M., Ferreau, J. (2015). Smartmill ${ }^{\mathrm{TM}}$ : Exceed your performance limits. Take full control of your grinding mills to increase productivity. ABB Switzerland Ltd., Local Business Unit Process Industries, ABB Whitepaper. Available at: https://library.e.abb.com/public/1f0ebafac7e1475db7662c43c106dc03/WhitePaper_Smart\%20Mill_LowRes.pdf?xsign=bdf + dz8b3S2SCnn7nFu7kw89X9AY0mIOQbnmca6E5hvkD3Yun2D9rXVxT+iJfDUP

[19] Francioli, D. M. (2015). Effect of operational variables on ball milling. UFRJ/ Escola Politécnica.

[20] Eric Forssberg, K. S., Subrahmanyam, T. V., Nilsson, L. K. (1993). Influence of grinding method on complex sulphide ore flotation: a pilot plant study. International Journal of Mineral Processing, 38 (3-4), 157-175. doi: https://doi.org/10.1016/03017516(93)90073-j

[21] Yin, W., Zhu, Z., Yang, B., Fu, Y., Yao, J. (2018). Contribution of particle shape and surface roughness on the flotation behavior of low-ash coking coal. Energy Sources, Part A: Recovery, Utilization, and Environmental Effects, 41 (5), $636-644$. doi: https://oi.org/10.1080/15567036.2018.1520346

[22] Szczerkowska, S., Wiertel-Pochopien, A., Zawala, J., Larsen, E., Kowalczuk, P. B. (2018). Kinetics of froth flotation of naturally hydrophobic solids with different shapes. Minerals Engineering, 121, 90-99. doi: https://doi.org/10.1016/j.mineng.2018.03.006

[23] Vizcarra, T. G., Harmer, S. L., Wightman, E. M., Johnson, N. W., Manlapig, E. V. (2011). The influence of particle shape properties and associated surface chemistry on the flotation kinetics of chalcopyrite. Minerals Engineering, 24 (8), 807-816. doi: https://doi.org/10.1016/j.mineng.2011.02.019 
[24] Koh, P. T. L., Hao, F. P., Smith, L. K., Chau, T. T., Bruckard, W. J. (2009). The effect of particle shape and hydrophobicity in flotation. International Journal of Mineral Processing, 93 (2), 128-134. doi: https://doi.org/10.1016/j.minpro.2009.07.007

[25] Xia, W. (2017). Role of particle shape in the floatability of mineral particle: An overview of recent advances. Powder Technology, 317, 104-116. doi: https://doi.org/10.1016/j.powtec.2017.04.050

[26] Ahmed, M. M. (2010). Effect of comminution on particle shape and surface roughness and their relation to flotation process. International Journal of Mineral Processing, 94 (3-4), 180-191. doi: https://doi.org/10.1016/j.minpro.2010.02.007

[27] Verrelli, D. I., Bruckard, W. J., Koh, P. T. L., Schwarz, M. P., Follink, B. (2012). Influence of particle shape and roughness on the induction period for particle-bubble attachment. XXVI International Mineral Processing Congress. New Delhi, 5665-5676.

[28] Ulusoy, U. (2003). Effect of Different Grinding Methods on the Critical Surface Tension of Wetting. Sivas.

[29] Yekeler, M., Ozkan, A., Austin, L. G. (2001). Kinetics of fine wet grinding in a laboratory ball mill. Powder Technology, 114 (1-3), 224-228. doi: https://doi.org/10.1016/s0032-5910(00)00326-0

[30] Allen, T. (1990). Particle size measurement. Springer. doi: https://doi.org/10.1007/978-94-009-0417-0

[31] Dapkunas, S. J., Jillavenkatesa, A. (2001). Particle Size Characterization. NIST Recommended Practice Guide. doi: https:// doi.org/10.6028/NBS.SP.960-1

[32] Particulate Systems. Available at: http://www.particulatesystems.com

[33] Ulusoy, U., Hiçy1lmaz, C., Yekeler, M. (2004). Role of shape properties of calcite and barite particles on apparent hydrophobicity. Chemical Engineering and Processing: Process Intensification, 43 (8), 1047-1053. doi: https://doi.org/10.1016/ j.cep.2003.10.003

[34] Hiçyilmaz, C., Ulusoy, U., Yekeler, M. (2004). Effects of the shape properties of talc and quartz particles on the wettability based separation processes. Applied Surface Science, 233 (1-4), 204-212. doi: https://doi.org/10.1016/j.apsusc.2004.03.209

[35] Particle Insight Manual (2013). Micromeritics ${ }^{\circledR}$ Instrument Corp., Particulate Systems 4356 Communications Drive Norcross, GA 30093. USA.

[36] Wotruba, H., Hoberg, H., Schneider, F. U. (1991). Investigation on the separation of microlithe and zircon. The influence of particle shape on floatability. Preprints. XVII International Mineral Processing Congress. Vol. 4. Dresden, 83.

[37] Ulusoy, U., Yekeler, M. (2005). Correlation of the surface roughness of some industrial minerals with their wettability parameters. Chemical Engineering and Processing: Process Intensification, 44 (5), 555-563. doi: https://doi.org/10.1016/j.cep. 2004.08.001

[38] Austin, L. G., Klimpel, R. R., Luckie, P. (1984). Process Engineering of Size Reduction: Ball Milling. New York: SME.

[39] Particle Insight Manual (2008). Micromeritics ${ }^{\circledR}$ Instrument Corp. Particulate Systems 4356 Communications Drive Norcross, GA 30093. USA.

[40] Orumwense, O. A., Forssberg, E. (1991). Surface and structural changes in wet ground minerals. Powder Technology, 68 (1), 23-29. doi: https://doi.org/10.1016/0032-5910(91)80060-v

[41] Vogel, L., Peukert, W. (2003). Breakage behaviour of different materials - construction of a mastercurve for the breakage probability. Powder Technology, 129 (1-3), 101-110. doi: https://doi.org/10.1016/s0032-5910(02)00217-6

[42] Bond, F. C. (1954). Control particle shape and size. Chem. Eng., 61, 195-198.

[43] Heywood, H. (1961). Powders in Industry. Soc. Chem. Ind., 25.

[44] Holt, C. B. (1981). The shape of particles produced by comminution. A review. Powder Technology, 28 (1), 59-63. doi: https:// doi.org/10.1016/0032-5910(81)87010-6

[45] Kaya, E., Hogg, R., Kumar, S. (2002). Particle Shape Modification in Comminution. KONA Powder and Particle Journal, 20 , 188-195. doi: https://doi.org/10.14356/kona.2002021

[46] Methods for PSD of powders. Part 4. Optical Methods (1963). British Standard 3406.

[47] Beyer, W. H. (1978). CRC Handbook of Mathematical Sciences. CRC Press, 982.

Received date 30.07.2020

Accepted date 07.09.2020

Published date 30.09.2020
(C) The Author(s) 2020

This is an open access article under the CC BY license (http://creativecommons.org/licenses/by/4.0). 